\title{
Incidence Rates for Tuberculosis Among HIV Infected Patients in Northern Tanzania
}

\author{
Edson W. Mollel ${ }^{1,2 *}$, Werner Maokola ${ }^{1,3}$, Jim Todd ${ }^{1,4}$, Sia E. Msuya ${ }^{1,5,6}$ and \\ Michael J. Mahande ${ }^{1}$
}

\begin{abstract}
${ }^{1}$ Department of Epidemiology and Biostatistics, Institute of Public Health, Kilimanjaro Christian Medical University College, Moshi, Tanzania, ${ }^{2}$ Northern Zone Blood Transfusion Center, Moshi, Tanzania, ${ }^{3}$ National AIDS Control Program, Dar es Salaam, Tanzania, ${ }^{4}$ Department of Population Health, London School of Hygiene and Tropical Medicine, London, United Kingdom, ${ }^{5}$ Department of Community Health, Institute of Public Health, Kilimanjaro Christian Medical University College, Moshi, Tanzania, ${ }^{6}$ Department of Community Medicine, KCMC Hospital, Moshi, Tanzania
\end{abstract}

\section{OPEN ACCESS}

Edited by:

Vitali Sintchenko,

University of Sydney, Australia

Reviewed by:

Pedro Xavier-Elsas,

Federal University of Rio de

Janeiro, Brazil

Carl-Magnus Svensson,

Leibniz Institute for Natural Product

Research and Infection

Biology, Germany

*Correspondence:

Edson W. Mollel

e.molle/@kcriac.tz

Specialty section: This article was submitted to Infectious Diseases - Surveillance,

Prevention and Treatment,

a section of the journal

Frontiers in Public Health

Received: 19 July 2019 Accepted: 07 October 2019

Published: 24 October 2019

Citation:

Mollel EW, Maokola W, Todd J,

Msuya SE and Mahande MJ (2019)

Incidence Rates for Tuberculosis

Among HIV Infected Patients in

Northern Tanzania.

Front. Public Health 7:306.

doi: 10.3389/fpubh.2019.00306
Background: HIV and tuberculosis (TB) are leading infectious diseases, with a high risk of co-infection. The risk of TB in people living with HIV (PLHIV) is high soon after sero-conversion and increases as the CD4 counts are depleted.

Methodology: We used routinely collected data from Care and Treatment Clinics (CTCs) in three regions in northern Tanzania. All PLHIV attending CTCs between January 2012 to December 2017 were included in the analysis. TB incidence was defined as cases started on anti-TB medications divided by the person-years of follow-up. Poisson regression with frailty models were used to determine incidence rate ratios (IRR) and 95\% confidence intervals $(95 \% \mathrm{Cl})$ for predictors of TB incidences among HIV positive patients.

Results: Among 78,748 PLHIV, 405 patients developed TB over 195,296 person-years of follow-up, giving an overall TB incidence rate of 2.08 per 1,000 person-years. There was an increased risk of TB incidence, 3.35 per 1,000 person-years, in hospitals compared to lower level health facilities. Compared to CD4 counts of $<350$ cells $/ \mu$, a high CD4 count was associated with lower TB incidence, $81 \%$ lower for a CD4 count of 350-500 cells/ $\mu$ I (IRR 0.19, 95\% Cl 0.04-0.08) and 85\% lower for those with a CD4 count above 500 cells/ $\mu$ I (IRR 0.15, 95\% Cl 0.04-0.64). Independently, those taking ART had 66\% lower TB incidences (IRR 0.34, 95\% Cl 0.15-0.79) compared to those not taking ART. Poor nutritional status and CTC enrollment between 2008 and 2012 were associated with higher TB incidences IRR 9.27 (95\% Cl 2.15-39.95) and IRR 2.97 (95\% Cl 1.05-8.43), respectively.

Discussion: There has been a decline in TB incidence since 2012, with exception of the year 2017 whereby there was higher TB incidence probably due to better diagnosis of TB following a national initiative. Among HIV positive patients attending CTCs, poor nutritional status, low CD4 counts and not taking ART treatment were associated with higher TB incidence, highlighting the need to get PLHIV on treatment early, and the need for close monitoring of CD4 counts. Data from routinely collected and available health services can be used to provide evidence of the epidemiological risk of TB.

Keywords: tuberculosis, HIV, Tanzania, incidence rates, sub-Saharan Africa 


\section{INTRODUCTION}

Tuberculosis (TB) is a disease caused by Mycobacteria tuberculosis, which can be latent in humans for a long time without clinical symptoms. Active TB can present as Pulmonary Tuberculosis (PTB) or Extra-Pulmonary Tuberculosis (EPTB), with cardinal features of fever, productive cough, hemoptysis, and weight loss, though the presentation among HIV infected individuals is often atypical. Several factors have been associated with an increased risk of TB incidence, such as poverty, malnutrition, and overcrowding, but the risk of active TB is 16-27 times higher in people living with HIV (PLHIV) compared to those who are HIV negative (1). This is due to the impaired and lowered innate and passive immunity against TB among PLHIV (2), increasing the risk of getting a new TB infection (3) and of progression from latent TB to active TB (3). New TB infections, rather than reactivation, account for $88 \%$ of new TB cases among PLHIV (4).

The risk of TB for PLHIV is high soon after sero-conversion (5), and continues to increase with depletion of CD4 count (6). The CD4 count is a diagnostic and/or prognostic marker that normally measures the number of CD4 expressing T-cells (also known as $\mathrm{T}$ helper cells). But the risk of TB among PLHIV decreases after starting anti-retroviral therapy (ART) (53).

TB incidence has been falling since 2013 , by $2 \%$ globally and by $4 \%$ in Africa. However, in 2017, 10 million (range 9-11.1 million) new cases of TB were reported worldwide, of which $25 \%$ occurred in Africa and $87 \%$ in 30 high TB burden countries (Tanzania included) (7). Of the cases, $90 \%$ were $>15$ years of age, $64 \%$ were males and $9 \%$ were HIV positive (7). The reported cases include only $51 \%$ of the estimated 920,000 new TB cases among PLHIV. Of the 1.5 million people enrolled at Care and Treatment Clinics (CTCs) in 2017, 8\% were diagnosed with TB in the same year. Africa accounted for $72 \%$ of all HIV associated TB cases in 2017 (7). The End TB Strategy has set a reduction target of $80 \%$ in TB incidence (new cases per 100,000 population per year), compared to the level in 2015 (7). Tanzania is one of the High TB Burden Countries, and one of the High TB/HIV Burden Countries. In Tanzania, it is estimated that of 154,000 (range 73,000-266,000) new cases of TB in 2017, 31\% (48,000 $[31,000-69,000])$ were also HIV positive (7). But with only $93 \%$ of TB patients in Tanzania having test results for HIV, of which $36 \%$ were co-infected with HIV, the true burden of TB among HIV positive people could be underestimated. TB has been the leading cause of death among HIV positive individuals (7), so a close monitoring of its occurrence in this subgroup of people is extremely important.

Several factors have been associated with TB incidence among HIV positive individuals including limited functional status, very low CD4 count $(<50$ cells $/ \mu \mathrm{l})(53)$, anemia, inappropriate vaccinations, cigarette smoking, households with a family size of 3 to 4 people, a lower social class, non-adherence to drugs and severe immunosuppression (8).

Several interventions have been implemented to try to reduce the incidence of $\mathrm{TB}$ in Tanzania's general population and among HIV positive individuals. As some patients may present with subclinical TB (9), WHO recommended active TB screening (intensified case finding) for all PLHIV, and infection control (10). In 2010, a gradual implementation of Genexpert MTB/RIF for the early diagnosis of $\mathrm{TB}$ among all $\mathrm{TB}$ suspects started, and was scaled up in 2013 (11). This test was initially only for HIV positive patients or for those with recurring TB. In 2011, the country introduced Isoniaziad Preventive Therapy (IPT) among PLHIV (12), which appears to be effective at reducing TB incidence (13). Recently, WHO is recommending a "test and treat" policy which requires all individuals being diagnosed as HIV positive to be put on ARVs immediately (14). Data from CTCs in Northern Tanzania provides an opportunity to track the incidence of TB among HIV patients through this spectrum of different intervention programs.

It is important to study TB incidence rates among PLHIV in Tanzania and compare it with the estimated global TB incidence rate that has been calculated by WHO (7). This can guide clinicians and policy makers on interventions and practices to improve health outcomes, and help to develop preventive measures to reduce the magnitude of the problem. This study determined the predictors and TB incidences among HIV positive patients since enrolment at Care and Treatment Centers (CTCs) after a follow up period of 6 years (January 2012 to December 2017), in the Northern part of Tanzania. Hence providing a big picture of the effects of several interventions that have been implemented over the years.

\section{METHODOLOGY}

\section{Study Design and Settings}

This was a retrospective cohort study which included data which have been routinely collected from patients attending CTCs from 1st January 2012 to 31st December 2017 in the Arusha, Kilimanjaro and Tanga regions. Both public and private CTCs were included, categorized as hospitals (at district level and above), health centers and dispensaries. At every visit, all HIV patients attending a CTC have a regular check-up, and a screening for opportunistic infections. The screening for TB follows WHO recommendations through the assessment of symptoms and signs. All these positive on the screening symptoms (either showing a productive cough, persistent low grade fever, night sweats, or weight loss) have to undergo further testing. This can be done using Genexpert MTB/RIF, or sputum microscopy at centers that have no Genexpert MTB/RIF. Genexpert MTB/RIF is a molecular diagnostic tool used for diagnosis of M. tuberculosis (MTB) and Resistance of these strains to Rifampicin (RIF). Sputum from the patient is mixed with Genexpert MTB/RIF buffer solution and is shaken and incubated for 5-10 $\mathrm{min}$, before being pipetted into cartridge of Genexpert MTB/RIF for computer assisted diagnosis. Those diagnosed with $\mathrm{TB}$ are given anti-TB medication.

\section{Study Population and Data Definitions}

All patients (above 15 years of age) who were HIV positive and attended one of 489 CTCs in the regions of Arusha, Kilimanjaro, and Tanga during the period of 1st January 2012 to 31st December 2017 were included in this study. Those who already had a TB diagnosis and/or were on TB treatment at the 
time of their first visit to the CTC were excluded, whilst those treated for TB before the start of the study duration were not excluded. The start time was taken to be 1st January 2012, or the date of first enrollment at the CTC if enrollment was after 1st January 2012. End time was defined as whichever came first among the following; the date there were last seen at a CTC, the date of death, the date of the first TB incidence, or 31st December 2017. A TB diagnosis was defined as being started on anti-TB medications after being screened for TB during a visit to a CTC, regardless of the method used to confirm a TB diagnosis. The following predictor variables were collected; age, sex, marital status, geographical location, baseline weight, baseline HIV WHO clinical stage, use of ARV, use of IPT, functional status, ARV adherence status, CTC enrollment year, type of ARV regimen, and baseline CD4 counts.

\section{Data Analysis}

Data were de-identified and analyzed using a statistical software package, STATA 15. After data cleaning, categorical data were summarized as frequencies and percentages. Continuous variables were summarized using their median and interquartile range (IQR) or by using their mean and standard deviation.

Incidence rates, and 95\% confidence intervals (95\%CI), for each level of independent variable were determined, as the number of newly diagnosed TB cases over the person-years at risk. Health facilities were used as a cluster variable, and Analysis of Variance (ANOVA) was used to compare aggregate rates of $\mathrm{TB}$ incidences by: health facility levels, health facility types (dispensaries, health centers, and hospitals), health facility ownership (private and public ownership) and regions (Arusha, Kilimanjaro, and Tanga). A Poisson regression model with frailty to adjust for the clustering at health facilities was used to obtain incidence rate ratios (IRR) for $\mathrm{TB}$, and 95\% CI for sociodemographic and clinical characteristics of the patients. Crude incidence rate ratios were then adjusted for other independent factors for TB.

\section{Ethical Clearance}

Ethical clearance was obtained from Kilimanjaro Christian Medical University College Research and Ethical Committee (Ethical clearance certificate number 2286). Permission from the Ministry of Health-Tanzania and NACP (National AIDS Control Program) authority to conduct the study was obtained. All patients' privacy and confidentiality were strictly observed throughout the study.

\section{RESULTS}

The study included 78,748 HIV-positive patients who were followed up for 195,296 person-years, with 405 patients recorded as having had a new episode of TB during the follow up, giving an incidence of TB of 2.08 (95\% CI 1.88-2.29) per 1,000 personyears (Table 1). Looking at ages, the highest incidence rates for TB, 2.45 per 1,000 person-years (95\% CI 2.01-2.99), were in patients aged 35-44 years of age. The TB incidence in males (Incidence $=3.70$ per 1,000 person-years, 95\% CI 3.21-4.27) was higher than in females (Incidence $=1.50$ per 1,000 person-years,
TABLE 1 | Incidence rates for TB by socio-demographic characteristics at enrolment into HIV services in 78,748 patients in three regions of Tanzania.

\begin{tabular}{|c|c|c|c|c|}
\hline Characteristics & $\begin{array}{c}\text { Number of } \\
\text { PLHIV }\end{array}$ & $\begin{array}{l}\text { Number of } \\
\text { TB cases }\end{array}$ & $\begin{array}{c}\text { Person-years } \\
\text { (in 1,000) }\end{array}$ & $\begin{array}{c}\text { Incidence rate } \\
\text { per } 1,000 \\
(95 \% \mathrm{Cl})\end{array}$ \\
\hline Overall & 78,748 & 405 & 195.1 & $2.08(1.88-2.29)$ \\
\hline \multicolumn{5}{|l|}{ Age } \\
\hline $15-24$ & 8,453 & 28 & 13 & $2.15(1.48-3.11)$ \\
\hline $25-34$ & 21,150 & 98 & 40 & $2.45(2.01-2.99)$ \\
\hline $35-44$ & 26,281 & 143 & 68.8 & $2.08(1.77-2.45)$ \\
\hline $45-55$ & 15,343 & 92 & 47.4 & $1.94(1.58-2.38)$ \\
\hline Above 55 & 7,521 & 44 & 26 & $1.70(1.26-2.28)$ \\
\hline \multicolumn{5}{|l|}{ Sex } \\
\hline Male & 21,983 & 188 & 50.7 & $3.70(3.21-4.27)$ \\
\hline Female & 56,764 & 217 & 144.4 & $1.50(1.31-1.72)$ \\
\hline \multicolumn{5}{|l|}{ Marital status } \\
\hline Cohabiting & 1,013 & 4 & 2.6 & $1.51(0.57-4.03)$ \\
\hline Divorced & 7,335 & 49 & 19 & $2.58(1.95-3.41)$ \\
\hline Married & 39,151 & 191 & 100.5 & $1.90(1.65-2.19)$ \\
\hline Single & 19,969 & 111 & 48.4 & $2.29(1.90-2.76)$ \\
\hline Widow/widower & 5,670 & 26 & 15.2 & $1.71(1.17-2.51)$ \\
\hline \multicolumn{5}{|l|}{ Region } \\
\hline Arusha & 12,348 & 45 & 19.3 & $2.30(1.74-3.12)$ \\
\hline Kilimanjaro & 26,133 & 134 & 66 & $2.03(1.71-2.41)$ \\
\hline Tanga & 40,267 & 226 & 109.9 & $2.06(1.81-2.34)$ \\
\hline \multicolumn{5}{|l|}{ Year of follow up } \\
\hline 2012 & 44,673 & 65 & 30.3 & $2.15(1.68-2.74)$ \\
\hline 2013 & 12,288 & 81 & 30.8 & $2.63(2.12-3.27)$ \\
\hline 2014 & 12,117 & 68 & 34 & $2.00(1.58-2.54)$ \\
\hline 2015 & 10,563 & 46 & 36.9 & $1.25(0.93-1.67)$ \\
\hline 2016 & 8,728 & 56 & 38.2 & $1.47(1.13-1.91)$ \\
\hline 2017 & 6,208 & 89 & 25.1 & $3.55(2.88-4.37)$ \\
\hline
\end{tabular}

95\% CI 1.31-1.72). Those who were divorced and those from Arusha region had higher TB incidences with incidence of 2.58 (95\% CI 1.95-3.41) and 2.30 (95\% CI of 1.74-3.12) per 1,000 person-years, respectively, than others (Table 1).

HIV patients with markers of lower immunity or advanced disease (HIV stage $3 \& 4, \mathrm{CD} 4<350$ cells/ $\mu$ l, lower weight and poorer nutritional status) had higher TB incidence than others (Table 2). Patients with a severely poor nutritional status had a TB incidence rate of 47.74 per 1,000 person-years (95\% CI 26.4486.21 ), while those with a moderately poor nutritional status had a TB incidence rate of 9.53 per 1,000 person-years (95\% CI 7.12-12.77), and those with an adequate nutritional status had a TB incidence rate of 1.73 per 1,000 person-years (95\% CI 1.54-1.95) (Table 2). Higher TB incidence rates was found in those who were bedridden (Incidence $=32.20$ per 1,000 personyears, 95\% CI 24.89-41.65) and those who were ambulatory (Incidence $=31.06$ per 1,000 person-years, 95\% CI 18.99-54.14), compared to those who were working (Incidence $=1.73$ per 1,000 person-years, 95\% CI 1.55-1.93) (Table 1).

Analysis of Variance (ANOVA) was used to compare rates of $\mathrm{TB}$ incidences across the following cluster variables: 
TABLE 2 | Incidence rates for TB by clinical characteristics at enrolment into HIV services in 78,748 patients in three regions of Tanzania.

\begin{tabular}{|c|c|c|c|c|}
\hline Characteristics & $\begin{array}{c}\text { Number of } \\
\text { PLHIV }\end{array}$ & $\begin{array}{l}\text { Number of } \\
\text { TB cases }\end{array}$ & $\begin{array}{c}\text { Person-years } \\
\text { per } 1,000\end{array}$ & $\begin{array}{l}\text { Incidence rate } \\
\text { per } 1,000 \\
(95 \% \mathrm{Cl})\end{array}$ \\
\hline \multicolumn{5}{|l|}{ Body weight } \\
\hline Below $40 \mathrm{~kg}$ & 5,276 & 68 & 7.7 & $8.88(7.00-11.27)$ \\
\hline 40-60kg & 44,135 & 263 & 100.9 & $2.61(2.31-2.94)$ \\
\hline Above 60 kg & 23,680 & 49 & 67.2 & $0.73(0.55-0.96)$ \\
\hline \multicolumn{5}{|l|}{ HIV WHO stage } \\
\hline Stage 1 & 17,347 & 18 & 28.4 & $0.63(0.40-1.01)$ \\
\hline Stage 2 & 17,390 & 28 & 37.2 & 0.75 (0.52-1.09) \\
\hline Stage 3 & 30,505 & 223 & 91.5 & $2.44(2.14-2.78)$ \\
\hline Stage 4 & 11,165 & 127 & 31.9 & 3.98 (3.34-4.73) \\
\hline \multicolumn{5}{|l|}{ CD4 categories } \\
\hline Below 350 & 7,808 & 42 & 12.6 & $3.33(2.46-4.51)$ \\
\hline 350-500 & 2,561 & 6 & 6.5 & $0.93(0.42-2.06)$ \\
\hline Above 500 & 3,098 & 4 & 9 & $0.44(0.17-1.19)$ \\
\hline \multicolumn{5}{|l|}{ Use of IPT } \\
\hline No & 78,504 & 405 & 193.7 & 2.09 (1.90-2.31) \\
\hline Yes & 244 & 0 & 1.5 & 0 \\
\hline \multicolumn{5}{|l|}{ Ever use ART } \\
\hline No & 5,428 & 72 & 17.9 & 4.03 (3.20-5.08) \\
\hline Yes & 73,320 & 333 & 177.3 & 1.88 (1.69-2.09) \\
\hline \multicolumn{5}{|l|}{ Functional status } \\
\hline Bedridden & 2,647 & 58 & 1.8 & $32.20(24.89-41.65)$ \\
\hline Ambulatory & 340 & 14 & 0.4 & $31.06(18.99-54.14)$ \\
\hline Working & 74,921 & 327 & 189 & 1.73 (1.55-1.93) \\
\hline \multicolumn{5}{|l|}{ CTC enroll year } \\
\hline 2003-2007 & 12,897 & 69 & 59.7 & $1.16(0.91-1.46)$ \\
\hline 2008-2012 & 32,057 & 131 & 83.5 & $1.57(1.32-1.86)$ \\
\hline 2013-2017 & 33,794 & 205 & 51.9 & $3.95(3.44-4.53)$ \\
\hline \multicolumn{5}{|l|}{ Nutritional status } \\
\hline Ok & 50,727 & 278 & 160.5 & $1.73(1.54-1.95)$ \\
\hline Moderate & 3,603 & 45 & 4.7 & $9.53(7.12-12.77)$ \\
\hline Severe & 218 & 11 & 0.2 & $47.74(26.44-86.21)$ \\
\hline \multicolumn{5}{|l|}{ ARV regimen } \\
\hline First line & 57,802 & 293 & 173.5 & 1.69 (1.51-1.89) \\
\hline Second line & 745 & 15 & 5.1 & 2.95 (1.78-4.89) \\
\hline Others & 512 & 0 & 0.4 & - \\
\hline
\end{tabular}

facility types (dispensaries, health centers and hospitals), facility ownership (private and public ownership) and regions (Arusha, Kilimanjaro, and Tanga). There was a significant increased risk of TB incidence in hospitals (3.35 per 1,000 person-years) compared to $\mathrm{TB}$ incidences in the health centers ( 1.28 per 1,000 personyears) and dispensaries (1.36 per 1,000 person-years), $p$-value 0.0306 . There were no statistically significant differences in TB incidences for the cluster variables of facility ownership and region (Table 3 ).

After performing a multilevel analysis and controlling for health facilities as clusters, several factors were significantly related to an increased TB incidence among HIV positive patients such as the year of enrollment at a CTC, those enrolled between
TABLE 3 | Comparison of cluster level's TB rates per 1,000 person-years.

\begin{tabular}{|c|c|c|c|c|c|}
\hline $\begin{array}{l}\text { Cluster } \\
\text { variables }\end{array}$ & $\begin{array}{l}\text { Number of } \\
\text { TB cases }\end{array}$ & $\begin{array}{l}\text { Number of } \\
\text { cluster } \\
\text { variables } \\
\text { with at least } \\
1 \text { TB case }\end{array}$ & $\begin{array}{c}\text { Mean/average } \\
\text { TB cases per } \\
\text { cluster } \\
\text { variable }\end{array}$ & $\begin{array}{l}\text { Average TB } \\
\text { rates per } \\
1,000 \\
\text { person-years } \\
\text { per cluster } \\
\text { variable }\end{array}$ & $\begin{array}{c}p \text {-value } \\
\text { (ANOVA) } \\
\text { comparing } \\
\text { TB rates for } \\
\text { cluster } \\
\text { variables }\end{array}$ \\
\hline \multicolumn{6}{|c|}{ Facility types } \\
\hline Dispensary & $y \quad 12$ & 38 & 0.32 & 1.36 & 0.0306 \\
\hline $\begin{array}{l}\text { Health } \\
\text { centers }\end{array}$ & 131 & 70 & 1.87 & 1.28 & \\
\hline Hospitals & 262 & 32 & 8.19 & 3.35 & \\
\hline Overall & 405 & 140 & 2.89 & 1.77 & \\
\hline \multicolumn{6}{|c|}{ Facility ownership } \\
\hline Private & 50 & 34 & 1.47 & 2.03 & 0.6632 \\
\hline Public & 355 & 106 & 3.35 & 1.69 & \\
\hline Overall & 405 & 140 & 2.89 & 1.77 & \\
\hline \multicolumn{6}{|l|}{ Region } \\
\hline Arusha & 45 & 39 & 1.15 & 1.86 & 0.6754 \\
\hline Kilimanjaro & 134 & 43 & 3.12 & 1.35 & \\
\hline Tanga & 226 & 58 & 3.9 & 2.03 & \\
\hline Overall & 405 & 140 & 2.89 & 1.77 & \\
\hline
\end{tabular}

2008 and 2012 had an IRR of 1.51 (95\% CI 1.12-2.03) while those enrolled between 2013 and 2017 had an IRR of 4.05 (95\% CI 3.04-5.39). Moderate and severe nutritional status were also significantly associated with TB incidence among HIV patients, with an IRR of 6.94 (95\% CI 4.92-9.80) and 28.05 (95\% CI 15.09-52.16), respectively. The use of second line ARVs had an IRR of 1.75 (95\% CI 1.04-2.97). The study found that several factors were protective against developing new TB among HIV patients, including being female and having CD4 count between 350 cells $/ \mu$ l to 500 cells/ $\mu$ l both of which were protective by $58 \%$, with IRRs of 0.42 (95\% CI $0.34-0.50)$ and 0.42 (95\% CI $0.21-$ $0.87)$, respectively. Using ARVs was protective by 57\%, IRR 0.43 (95\% CI 0.33-0.55). CD4 counts above 500 cells/ $\mu$ l was protective by $84 \%$, IRR 0.16 (95\% CI $0.07-0.42)$ and having a working functional status, were even more protective, by $95 \%$, IRR 0.05 (95\% CI 0.04-0.07) (Table 4).

After adjusting for both health facility type clusters and other important factors, only two factors were found to be significantly positively-related to incidence of $\mathrm{TB}$, which are severe malnutrition, IRR 9.27 (95\% CI 2.15-39.95), and being enrolled at a CTC between the years 2008 and 2012, IRR 2.97 (95\% CI 1.05-8.43), compared to being enrolled in the years 2003 to 2007. The following factors remained as significantly protective against TB incidence among HIV patients after doing multilevel analysis. Having CD4 counts above 350 cells/ $\mu 1$ with IRRs of 0.19 (95\% CI $0.04-0.80)$ and 0.15 (95\% CI 0.04-0.64) for CD4 counts between 350 and 500 cells/ $\mu$ l and above 500 cells $/ \mu \mathrm{l}$, respectively. Use of ART was protective by $66 \%$, IRR 0.34 (95\% CI 0.15-0.79), while a working functional status was protective against TB incidence by $85 \%$, IRR 0.15 (95\% CI $0.05-$ 0.47) (Table 4). In this multilevel model and controlling for health facility types as variable clusters, the intercept variability across facilities was 0.78 (95\% CI 0.23-2.73), with standard error (SE) of 0.5 . 
TABLE 4 | Poisson regression with multilevel analysis of the determinants of TB incidence in Northern Tanzania.

\begin{tabular}{|c|c|c|c|c|c|}
\hline Characteristics & \multicolumn{2}{|c|}{$\begin{array}{c}\text { Survival status } \\
\text { event } \\
\text { (TB) censored }\end{array}$} & \multirow[t]{2}{*}{ Crude hazard ratio $(95 \% \mathrm{C})$} & \multirow[t]{2}{*}{$\begin{array}{l}\text { Adjusted hazard ratio }(95 \% \mathrm{Cl}) \\
\text { adjusting only for clusters }\end{array}$} & \multirow[t]{2}{*}{$\begin{array}{l}\text { AHR }(95 \% \mathrm{Cl}) \text { adjusting for other } \\
\text { factors and for clusters }\end{array}$} \\
\hline Age & & & & & \\
\hline $15-24$ & 28 & 8,425 & 1 & 1 & 1 \\
\hline $25-34$ & 98 & 21,052 & $1.16(0.75-1.74)$ & $1.19(0.78-1.81)$ & $1.01(0.28-3.70)$ \\
\hline $35-44$ & 143 & 26,138 & $0.95(0.63-1.42)$ & $0.97(0.65-1.46)$ & $0.46(0.12-1.75)$ \\
\hline $55-55$ & 92 & 15,251 & $0.87(0.57-1.33)$ & $0.89(0.58-1.36)$ & $0.52(0.13-2.11)$ \\
\hline Above 55 & 44 & 7,477 & $0.75(0.47-1.21)$ & $0.78(0.48-1.25)$ & $0.60(0.13-2.77)$ \\
\hline \multicolumn{6}{|l|}{ Sex } \\
\hline Male & 188 & 21,795 & 1 & 1 & 1 \\
\hline Female & 217 & 56,547 & $0.43(0.36-0.52)$ & $0.42(0.34-0.50)$ & $0.89(0.41-1.92)$ \\
\hline \multicolumn{6}{|l|}{ CD4 categories } \\
\hline Below 350 & 42 & 7,766 & 1 & 1 & 1 \\
\hline $350-500$ & 6 & 2,555 & $0.41(0.20-0.84)$ & $0.42(0.21-0.87)$ & $0.19(0.04-0.80)$ \\
\hline Above 500 & 4 & 3,094 & $0.16(0.06-0.40)$ & $0.16(0.07-0.42)$ & $0.15(0.04-0.64)$ \\
\hline \multicolumn{6}{|l|}{ Ever use art } \\
\hline No & 51 & 5,356 & 1 & 1 & 1 \\
\hline Yes & 354 & 72,987 & $0.46(0.36-59)$ & $0.43(0.33-0.55)$ & $0.34(0.15-0.79)$ \\
\hline \multicolumn{6}{|l|}{ Functional status } \\
\hline Bedridden & 58 & 2,589 & 1 & 1 & 1 \\
\hline Ambulatory & 14 & 326 & $0.97(0.56-1.71)$ & $0.92(0.52-1.63)$ & $2.14(0.23-19.94)$ \\
\hline Working & 327 & 74,594 & $0.05(0.04-0.07)$ & $0.05(0.04-0.07)$ & $0.15(0.05-0.47)$ \\
\hline \multicolumn{6}{|l|}{ CTC enroll year } \\
\hline 2003-2007 & 45 & 12,828 & 1 & 1 & 1 \\
\hline 2008-2012 & 155 & 31,926 & $1.37(1.03-1.84)$ & $1.51(1.12-2.03)$ & $2.97(1.05-8.43)$ \\
\hline 2013-2017 & 205 & 33,589 & 3.50 (2.66-4.59) & 4.05 (3.04-5.39) & 2.55 (0.79-8.20) \\
\hline \multicolumn{6}{|l|}{ Nutritional status } \\
\hline OK & 278 & 50,449 & 1 & 1 & 1 \\
\hline Moderate & 45 & 3,558 & $5.53(4.04-7.58)$ & $6.94(4.92-9.80)$ & $0.93(0.20-4.22)$ \\
\hline Severe & 11 & 207 & 27.95 (15.30-51.06) & 28.05 (15.09-52.16) & 9.27 (2.15-39.95) \\
\hline
\end{tabular}

\section{DISCUSSION}

In this population of PLHIV attending CTCs for the years 2012 to 2017, in Northern Tanzania, the incidence rate of TB was 2.08 per 1,000 person-years, which is higher than the general TB incidence rate of 1.29 per 1,000 Tanzanian general population, for the year 2016, as reported by the Tanzania National TB and Leprosy Program (NTLP), but lower than the WHO TB incidence estimation of 2.7 per 1,000 population, in the year 2017 (7). But this number is within the estimated range of 1.5-4 new cases per 1,000 in most of the 30 high TB burden countries among the general population. Our estimated incidence rate is lower than other studies done in Tanzania, which showed an incidence of TB among HIV patients to be in the range of 8-17 per 1,000 person-years (15), but this was between the years of 2008 to 2010 for patients who were not on ART and before the introduction of IPT. Another study done in a major city in Tanzania, Dar es Salaam, found the incidence rate to be 27 per 1,000 person-years (13). The city is highly crowded, has a high TB diagnostic capacity and according to NTLP has the highest TB case notification rate in the country. In Nigeria, TB incidence was 5.7 per 1,000 personyears, among HIV patients on ARVs for the period of 2004 to 2012 (16). Higher incidences were found in South Africa (17) and Ethiopia (18) with TB incidences of 44 per 1,000 person-years and 86 per 1,000 person-years, respectively. According to WHO incidence rates need to be falling by $4-5 \%$ per year up to 2020 , in order to reach the End TB Strategy milestone.

A study in Nigeria (16) and another in South Africa (17), found males to have higher TB incidence than females. Age is also associated with TB incidence with patients aged 2534 years having the highest incidence, while those aged 1524 years having the lowest incidence trend (Figure 1). This agrees with other studies performed in Ethiopia (18) and Nigeria (16). Age and sex differences in TB incidence could be due to cultural factors and economical reasons, whereby men and those in the most economically productive age group are less likely to have time to attend clinics and to receive appropriate care, including Isoniazid Preventive Therapy, hence are more likely to be diagnosed with TB (Figure 2). Other studies have shown that males have an increased TB prevalence than females 


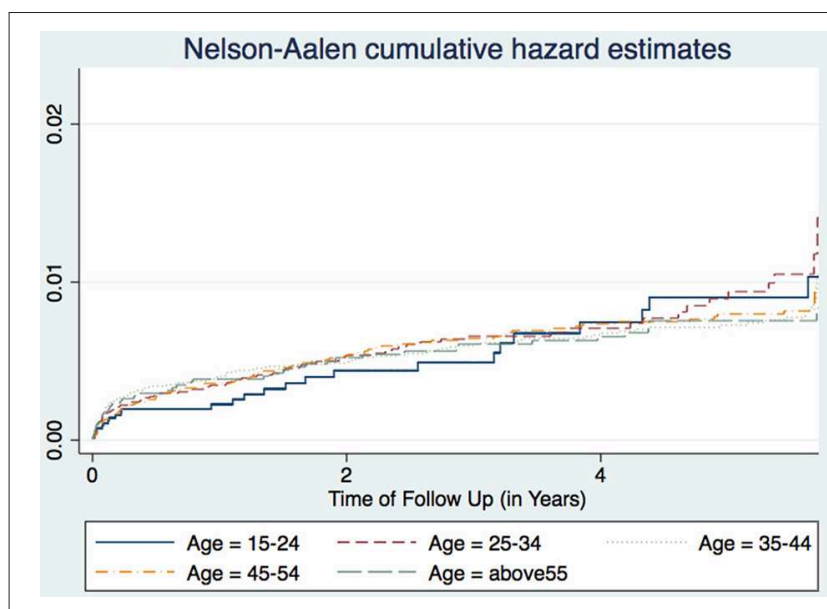

FIGURE 1 | Cumulative hazard estimates (TB incidences) for age categories.

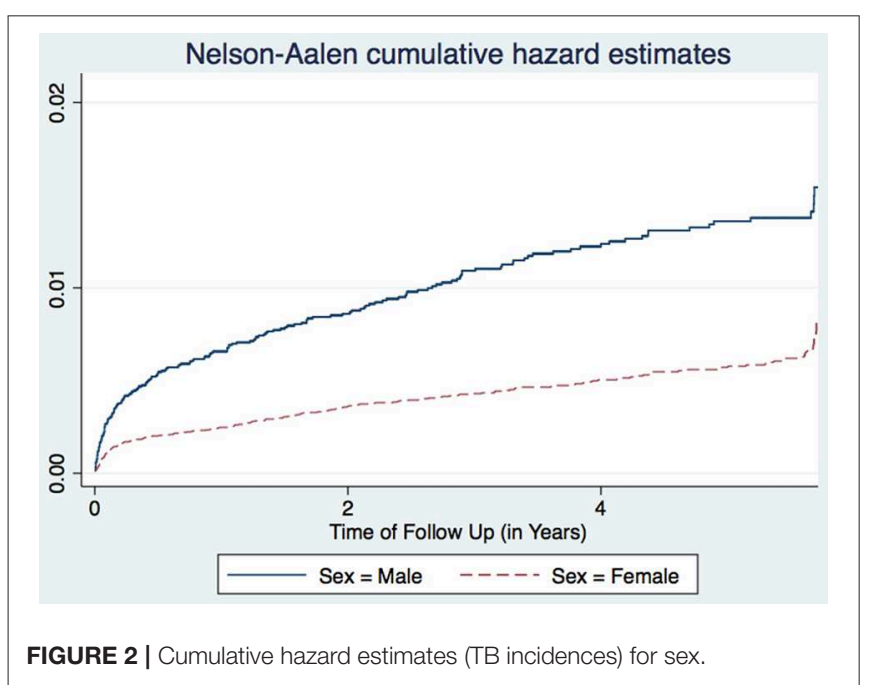

(especially in low- and middle-income countries) due to the fact that men are disadvantaged in seeking and/or accessing TB care in many settings (19). The same pattern has also been observed in Europe (20).

The three regions of Arusha, Kilimanjaro, and Tanga had essentially similar TB incidence rates, and there were no significant differences between public and private facilities. All health facilities in this dataset had at least one TB case, and PLHIV seen at the hospitals for care and treatment had higher TB occurrence than those attending lower level facilities. This may be due to the fact that many lower level facilities have poor or inadequate availability of diagnostic equipment, and have low skilled health care workers. Hence leading to a reduced capacity for diagnosing $\mathrm{TB}$ as these co-infected patients tend to present with atypical $\mathrm{TB}$ manifestations which are difficult to diagnose. However, this could also have been due to the referral mechanisms, whereby most PLHIV with more advanced HIV and probably with active TB tend to be referred to hospitals for advanced care and treatment. In addition, most of these lower level facilities do not hospitalize their patients. This observation

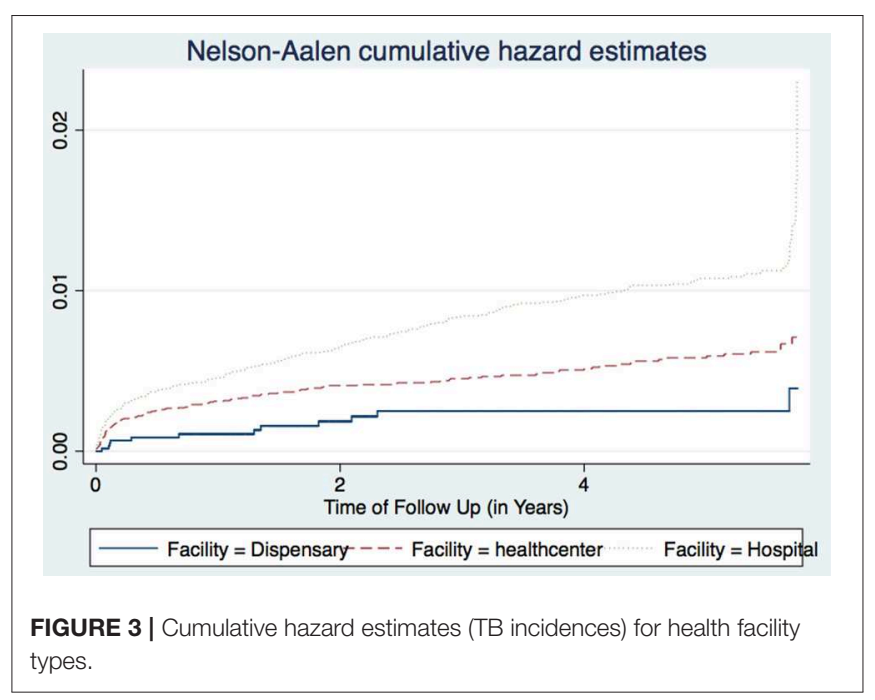

was more pronounced in the later years of the study, after the increased roll out of Genexpert MTB/RIF machines to many higher level facilities (Figure 3).

Severe malnutrition was found to be associated with an increased risk of TB among HIV patients in our study. Similar findings have been observed in other settings, especially among children (21) where malnutrition accounts for $26 \%$ of incident TB (22). It is also positively associated with TB progression (23), poor treatment outcomes (21) and delayed recovery (24). This is because it deteriorates the cell mediated and humoral immunity (21). Though most of the studies have focused on children, malnutrition is common among adult TB patients (25), as well as MDRTB patients (26) and in patients with other infections (27). Strategies to manage malnutrition should incorporate routine TB and HIV screening (28), and modifications to TB treatment (29), though some studies have found that these additional strategies are not yet effective (22) and that there is no significant association between nutritional status and TB severity (30). Even though this is controversial, but if implemented effectively, these strategies might prevent $\mathrm{TB}$ incidence and increase the probability of being cured $(21,31)$, and decrease the risk of TB mortality especially among children (32).

Incident TB increased almost three times for those enrolled in CTCs between 2008 and 2017 compared to those enrolled between 2003 and 2007, the reason for which could be that most of those enrolled between 2003 and 2007 were already on ARVs for some time when we started following up in 2012. In general TB incidence among HIV patients has been declining since 2012, with the exception being during 2017. This decline is congruent with the recent global and African data on TB epidemiological burden, that there has been a consistent decline in TB over the last decade, as well as in the most affected areas of Sub Saharan Africa (7). Success can be attributed to an improved health system; increased use of Isoniazid preventive therapy; increased HIV prevention and awareness (33); early TB diagnosis (11) and treatment; all of which reduces the risk of TB transmission, whilst also strengthening the collaboration between HIV and TB control activities when combined with other diseases. For the year 2017, which had a higher incidence of 3.54 per 1,000 person-years 
(Table 1), this could be attributed to the increased roll out of Genexpert MTB/RIF and that probability that most hospitals had these molecular tests installed.

Our findings have shown that a CD 4 count above 350 cells/ $\mu 1$, or being on ARVs, was protective against the development of incident TB. HIV increases TB risk through increasing the risk of acquiring TB (3), or through reactivation of latent TB (2). Immunity against other infections including TB is compromised by HIV infection (34). The risk doubles after sero-conversion (5) and remains high within the first 3 years after enrollment at CTCs (18). TB risk is five times higher in the African region (1), and especially for those with a history of previous TB disease (15), and with a decreasing CD4 count (6), similar to our findings. As found in other studies (35), the risk of TB incidence is there even among HIV patients who are on IPT. The risk decreases with the use of ARVs (33) as our study has found but can still remain 5 times higher compared to HIV uninfected persons (36) despite an increase in their CD4 count. ART benefits are more pronounced in preventing TB in patients with a lower CD4 count (37), this is because ARVs in general restore immunity and so protect against developing TB, but this is controversial as other studies have found that ART use does not reduce TB incidence (38). Even so, this ART protection seems to be lost when one is on second line ARVs (39) as was also found in this study. Others have suggested controlling for hemoglobin levels as low hemoglobin can be used as a predictor of TB among these patients on ARVs (40).

Working functional status was significantly protective against TB incidence as found in other studies (53). Other studies found the risk factors for TB among HIV patients to be low hemoglobin (40), increased HIV viral load (41), genetics (42), WHO HIV stage 3, not taking Isoniazid (43), smoking, diabetes, alcohol use, crowded living, poverty (44), variation in compliance to taking ARTs (45), as well as social inequality in access to sanitation and health expenditure per capita. Other studies have shown that the following subpopulations have an increased risk of TB incidence: prisoners (46), migrants (47), health care workers (48), miners (4), and contacts of indexed TB cases (49). Other studies have found that other protective factors against TB incidence include the use of IPT $(13,50)$, cash transfers $(51)$, as well as early TB detection and treatment initiation (52).

This study's strengths include the use of routinely collected data from a large number of patients and the inclusion of all health facilities providing electronic data for HIV care and treatment across the three regions. It has also assessed and adjusted for the differences between health facilities that might affect TB incidence. The study was limited in that only HIV positive patients who were identified to have a definitive diagnosis of TB, or to have started TB medications, during follow up were considered as TB incidence. The analysis has included all new cases of TB, including those with no microbiological TB confirmation. However, there could be an underestimation of new TB cases among HIV patients if there were no diagnostic tools available for presumptive TB cases (especially in lower level health facilities), or if there was a delay or gap between the diagnosis of $\mathrm{TB}$ and starting anti-TB medications. We recommend future studies on determining the mechanisms of nutritional effects on $\mathrm{TB}$ incidence and progression; the association between second line ARVs and TB incidence; and determining why the risk of $\mathrm{TB}$ remains higher even after improving the CD4 count of HIV patients on ART. We also recommend further analysis of the $\mathrm{TB}$ diagnosis cascade to see how effective the system is for TB diagnosis.

\section{CONCLUSION}

Despite the prolonged decline of TB burden in most of the African countries, in the last decade TB is still a public health problem especially among HIV patients. Poor nutritional status and being enrolled at the CTCs after 2007 were significantly associated with TB incidence among HIV patients attending CTCs since 2003 in Tanzania. So there needs to be effective collaborative TB control strategies encompassing other diseases including HIV, and a continuing improvement of health system including the CTCs. Having a working functional status, a high CD4 count (above 350 cells/ $\mu \mathrm{l}$ ), and using ART were protective against TB incidence among HIV positive patients, though the use of second line ARVs was found to be a risk factor for developing TB. So all patients should be put on ARVs as soon as possible, and close monitoring of all patients with a CD4 count $<350$ cells/ $\mu$ l.

\section{DATA AVAILABILITY STATEMENT}

Study's data can be accessed from EM after permission and approval from the NACP and the Government of Tanzania.

\section{AUTHOR CONTRIBUTIONS}

EM, JT, MM, and SM designed the study and wrote the manuscript. EM, JT, and WM retrieved the data. EM and JT analyzed the data. All authors approved the final version of the manuscript.

\section{FUNDING}

EM received funding through the SEARCH Project for his $\mathrm{PhD}$ studies under which this analysis was conducted. The SEARCH project was funded by the Bill and Melinda Gates Foundation (OPP1084472).

\section{ACKNOWLEDGMENTS}

Thanks to all staff of Kilimanjaro Christian Medical University College and National AIDS Control Program for their inputs and support in making this work complete. EM is a $\mathrm{PhD}$ student, and this work is part of the PhD project that was funded by the SEARCH PROJECT (Sustainable Evaluation through Analysis of Routinely Collected HIV data), a collaboration between the London School of Hygiene and Tropical Medicine and the Ministry of Health in Tanzania, and is funded by Bill and Melinda Gates Foundation entitled Using routinely collected public facility data for program improvement in Tanzania, Malawi and Zambia (OPP1084472). 


\section{REFERENCES}

1. Harries AD, Zachariah R, Corbett EL, Lawn SD. The HIV- associated tuberculosis epidemic-when will we act? Lancet. (2010) 375:1906-19. doi: 10.1016/S0140-6736(10)60409-6

2. Selwyn PA, Hartel D, Lewis VA, Schoenbaum EE, Vermund SH, Klein RS, et al. A prospective study of the risk of tuberculosis among intravenous drug users with human immunodeficiency virus infection. $N$ Engl J Med. (1989) 320:545-50. doi: 10.1056/NEJM1989030232 00901

3. Corbett EL, Charalambous S, Moloi VM, Fielding K, Grant AD, Dye C, et al. Human immunodeficiency virus and the prevalence of undiagnosed tuberculosis in African gold miners. Am J Resp Crit Care Med. (2004) 170:6739. doi: 10.1164/rccm.200405-590OC

4. Charalambous S, Grant AD, Moloi V, Warren R, Day JH, van Helden P, et al. Contribution of re-infection to reccurent tuberculosis in South African gold miners. Int J Tuberc Lung Dis. (2008) 12:942-8.

5. Sonnenberg P, Glynn JR, Fielding K, Murray J, Godfrey-Faussett P, Shearer S. How soon after infection with HIV does the risk of tuberculosis start to increase? A retrospective cohort study in South African gold miners. J Infect Dis. (2005) 191:150-8. doi: 10.1086/426827

6. Lawn SD, Myer L, Edwards D, Bekker LG, Wood R. Short-term and long-term risk of tuberculosis associated with CD4 cell recovery during antiretroviral therapy in South Africa. AIDS. (2009) 23:1717-25. doi: 10.1097/QAD.0b013e32832d3b6d

7. WHO (2018). Global Tuberculosis Report 2018. World Health Organization (2018).

8. Iroezindu MO, Ofondu EO, Mbata GC, van Wyk B, Hausler HP, Dh A, et al. Factors associated with prevalent tuberculosis among patients receiving highly active antiretroviral therapy in a Nigerian Tertiary Hospital. Ann Med Health Sci Res. (2016) 120-8. doi: 10.4103/2141-9248.181837

9. Mtei L, Matee M, Herfort O, Bakari M, Horsburgh CR, Waddell R, et al. High rates of clinical and subclinical tuberculosis among HIV-infected ambulatory subjects in Tanzania. Clin Infect Dis. (2005) 40:1500-7. doi: 10.1086/ 429825

10. WHO. WHO policy on collaborative TB/HIV activities: guidelines for national programmes and other stakeholders. In: WHO Policy on Collaborative TB/HIV Activities: Guidelines for National Programmes and Other Stakeholders. WHO (2012)

11. Mollel E, Lekule I, Lynen L, Decroo T. Effect of reliance on Xpert MTB/RIF on time to treatment and multidrug-resistant tuberculosis treatment outcomes in Tanzania: a retrospective cohort study. Int Health. (2019) 11:ihz005. doi: 10.1093/inthealth/ihz005

12. Ramadhani A, Josiah RM, Rwebembera A, Msuya EL, Swai R, Urassa P, et al. National Guidelines for the Management of HIV and AIDS. NACP, Ministry of Health and Social Welfare (2013).

13. Sabasaba A, Mwambi H, Somi G, Ramadhani A, Mahande MJ. Effect of Isoniazid Preventive Therapy on tuberculosis incidence and associated factors among HIV infected adults in Tanzania: a retrospective cohort study. BMC Infect Dis. (2019) 19:62. doi: 10.1186/s12879-019-3696-x

14. WHO. Prevent HIV, Test and Treat All - WHO Support for Country Impact. Progress Report 2016 (2016).

15. Said K, Verver S, Kalingonji A, Lwilla F, Mkopi A, Charalambous S, et al. Tuberculosis among HIV-infected population: incidence and risk factors in rural Tanzania. Afr Health Sci. (2017) 17:208-15. doi: 10.4314/ahs.v17i1.26

16. Pathmanathan I, Dokubo EK, Shiraishi RW, Agolory SG, Auld AF, Onotu D., et al. Incidence and predictors of tuberculosis among HIV-infected adults after initiation of antiretroviral therapy in Nigeria, 2004-2012. PLoS ONE. (2017) 12:e0173309. doi: 10.1371/journal.pone.0173309

17. Bock P, Jennings K, Vermaak R, Cox H, Meintjes G, Fatti G, et al. Incidence of tuberculosis amongst HIV positive individulas initiating antiretroviral treatment at higher CD4 counts in the HPTN 071(popART) trial in South Africa. J Acquir Immune Defic Syndr. (2018) 77:93-101. doi: 10.1097/QAI.0000000000001560

18. Ahmed A, Mekonnen D, Shiferaw AM, Belayneh F, Yenit MK. Incidence and determinants of tuberculosis among adult patients with HIV attending HIV care in north-east Ethiopia; a retrospective cohort study. BMJ Open. (2018) 8:e016961. doi: 10.1136/bmjopen-2017-016961
19. Horton KC, MacPherson P, Houben RM, White RG, Corbett EL. Sex differences in tuberculosis burden and notifications in low- and middleincome countries: a systematic review and meta-analysis. PLoS Med. (2016) 13:e10021119. doi: 10.1371/journal.pmed.1002119

20. Marcoa R, Ribeiro AI, Zão I, Duarte R. Tuberculosis and gender -risk factors influencing the risk of tuberculosis among men and women by age group. Pulmonology. (2018) 24:199-202. doi: 10.1016/j.pulmoe.2018.03.004

21. Jaganath D, Mupere E. Childhood Tuberculosis and Malnutrition. JID. (2012) 206:1809-15. doi: 10.1093/infdis/jis608

22. Bhat PG, Kumar AMV, Naik B, Satyanarayana S, Deepak KG, Nair SA, et al. Intensified Tuberculosis Case finding among malnourished children in nutritional rehabilitation centers of Karnataka, India: Missed opportunities. PLoS ONE. (2013) 8:e84255. doi: 10.1371/journal.pone.0084255

23. Matteelli A, Rendon A, Tiberi S, Al-Abri S, Voniatis C, Carvalho ACC, et al. Tuberculosis elimination: where are we now? Eur Respir Rev. (2018) 27:180035. doi: 10.1183/16000617.0035-2018

24. Gupta KB, Gupta R, Atreja A, Verma M, Vishvkarm S. Tuberculosis and Nutrition. Lung India. (2009) 26:9-16. doi: 10.4103/0970-2113.45198

25. Das S, Sen S, Debnath A, Basuthakur S, Saha PK, Biswas C, et al. A study of nutritional assessment of newly diagnosed tuberculosis patients in a tertiary care hospital of Tripura, India. Int J Res Med Sci. (2018) 6:1382-7. doi: 10.18203/2320-6012.ijrms20181301

26. Nyaki FS, Taksdal M, Mbuya AW, Sariko M, Lekule IA, Kisonga RM, et al. Predictors of nutritional status in patients treated for multidrug-resistant tuberculosis at a referral hospital in Tanzania. J Clin Infect Dis Pract. (2016) 1:115. doi: 10.4172/2476-213X.1000115

27. Jones KDJ, Berkley JA. Severe acute malnutrition and infection. Paediatr Int Child Health. (2014) 34(Suppl. 1):S1-29. doi: 10.1179/2046904714Z.000000000218

28. De Maayer T, Saloojee H. Clinical outcomes of severe malnutrition in a high tuberculosis and HIV setting. Arch Dis Child. (2011) 96:560-4. doi: 10.1136/adc.2010.205039

29. Oshikoya KA, Senbanjo IO. Caution when treating tuberculosis in malnourished children. Arch Dis Child. (2018) 103:1101-3. doi: 10.1136/archdischild-2018-314972

30. Hoyt K. Effect of malnutrition on tuberculosis microbiologic severity in India (theses and dissertations). Boston: Boston University (2015).

31. Leveri TH, Lekule I, Mollel E, Lyamuya F, Kilonzo K. Predictors of Treatment outcomes among multidrug resistant tuberculosis patients in Tanzania. Tubercul Res Treat. (2019) 2019:3569018. doi: 10.1155/2019/3569018

32. Munthali T, Chabala C, Chama E, Mugode R, Kapata N, Musonda P, et al. Tuberculosis caseload in children with severe acute malnutrition related with high hospital based mortality in Lusaka, Zambia. BMC Res Notes. (2017) 10:206. doi: 10.1186/s13104-017-2529-5

33. Surie D, Borgdorff MW, Cain KP, Click ES, DeCock KM, Yuen CM. Assessing the impact of antiretroviral therapy on tuberculosis notification rates among people with HIV: a descriptive analysis of 23 countries in sub-Saharan Africa 2010-2015. BMC Infect Dis. (2018) 18:481. doi: 10.1186/s12879-018-3387-z

34. Diedrich CR, Flynn JL. HIV-1/Mycobacterium tuberculosis co-infection immunology: how does HIV-1 exacerbate tuberculosis? Infect Immun. (2011) 79:1407-17. doi: 10.1128/IAI.01126-10

35. Yirdaw KD, Teklu AM, Mamuye AT, Zewdu S. Breakthrough tuberculosis disease among people with HIV-Should we be worried? A retrospective longitudinal study. PLoS ONE. (2019) 14:e0211688. doi: 10.1371/journal.pone.0211688

36. Naidoo K, Karim QA, Bhushan A, Naidoo K, Yende-Zuma N, McHunu $\mathrm{PK}$, et al. High rates of tuberculosis in patients accessing HAART in rural South Africa. J Acquir Immune Defic Syndr. (2014) 65:438-46. doi: 10.1097/QAI.0000000000000060

37. Stöhr W, Back D, Dunn D, Sabin C, Winston A, Gilson R, et al. Factors influencing efavirenz and nevirapine plasma concentration: effect of ethnicity, weight and co-medication. Antivir Ther. (2008) 13:675-85.

38. Zeldow B, Kim S, McSherry G, Cotton MF, Jean-Philippe P, Violari A, et al Use of antiretrovirals in HIV- infected child in a tuberculosis prevention trial: IMPAACT P1041. Int J Tuberc Dis. (2017) 21:38-45. doi: 10.5588/ijtld. 16.0149

39. Mave V, Kadam D, Salvi S, Basavaraj A, Chandanwale A, Joshi S, et al. High TB Risk in HIV-Positive Patients On Second Line Antiretrovirals in Pune, 
India. The Foundation for AIDS Research, as a part of the International Epidemiologic Databases to Evaluate AIDS. Boston, MA (2016).

40. Kerkhoff AD, Wood R, Cobelens FG, Gupta-Wright A, Bekker LG, Lawn SD. The predictive value of current haemoglobin levels for incident tuberculosis and/or mortality during long-term antiretroviral therapy in South Africa; a cohort study. BMC Med. (2015) 13:70. doi: 10.1186/s12916-0150320-9

41. Fenner L, Atkinson A, Boulle A, Fox MP, Prozesky H, Zürcher K, et al. HIV viral load as an independent risk factor for tuberculosis in South Africa: collaborative analysis of cohort studies. J Int AIDS Soc. (2017) 20:21327. doi: 10.7448/IAS.20.1.21327

42. Raghavan S, Alagarasu K, Selvaraj P. Immunogenetics of HIV and HIV associated tuberculosis. Tuberculosis. (2012) 92:18-30. doi: 10.1016/j.tube.2011.08.004

43. Negussie A, Debalke D, Belachew T, Tadesse F. Tuberculosis co-infection and its associated factors among people living with HIV/AIDS attending antiretroviral therapy clinic in southern Ethiopia: a facility based retrospective study. BMC Res Notes. (2018) 11:417. doi: 10.1186/s13104-018-3530-3

44. Hoy D, Kienene T, Reiher B, Roth A, Tira T, McKenzie J, et al. Battling tuberculosis in an island context with a high burden of communicable and non-communicable diseases; epidemiology, progress, and lessons learned in Kiribati, 2000 to 2012. Int J Infect Dis. (2015) 30:135-41. doi: 10.1016/j.ijid.2014.11.025

45. Auld AF, Blain M, Ekra KA, Kouakou JS, Ettiègne-Traoré V, Tuho MZ, et al. Wide variations in compliance with tuberculosis screening guidelines and tuberculosis incidence between antiretroviral therapy facilities-Cote d'Ivore. PLoS ONE. (2016) 11:e0157059. doi: 10.1371/journal.pone.0157059

46. McDaniel CJ, Chitnis AS, Barry PM, Shah N. Tuberculosis trends in California correctional facilities, 1993-2013. Int J Tuberc Lung Dis. (2017) 21:922-9. doi: $10.5588 /$ ijtld. 16.0855

47. Tavares AM, Fronteira I, Couto I, Machado D, Viveiros M, Abecasis AB, et al. HIV and tuberculosis co-infection among migrants in Europe: a systematic review on the prevalence, incidence and mortality. PLOS ONE. (2017) 12:e0185526. doi: 10.1371/journal.pone.0185526
48. Tudor C, Van der Walt M, Margot B, Dorman SE, Pan WK, Yenokyan G, et al. Tuberculosis among health care workers in Kwazulu-Natal, South Africa: a retrospective cohort analysis. BMC Public Health. (2014) 14:891. doi: 10.1186/1471-2458-14-891

49. van Schalkwyk C, Variava E, Shapiro AE, Rakgokong M, Masonoke K, Lebina L, et al. Incidence of TB and HIV in prospectively followed household contacts of TB index patients in South Africa. PLoS ONE. (2014) 9:e95372. doi: 10.1371/journal.pone.0095372

50. Mueller Y, Mpala Q, Kerschberger B, Rusch B, Mchunu G, Mazibuko S, et al. Adherence, tolerability, and outcome after 36 months of isoniazid preventive therapy in 2 rural clinics of Swaziland: a prospective observational feasibiltiy study. Medicine. (2017) 96:35. doi: 10.1097/MD.0000000000007740

51. Rudgard WE, Carter DJ, Scuffell J, Cluver LD, Fraser-Hurt N, Boccia D. Cash transfers to enhance tuberculosis control; lessons from the HIV response. BMC Public Health. (2018) 18:1052. doi: 10.1186/s12889-018-5962-z

52. Knight GM, Dodd PJ, Grant AD, Fielding KL, Churchyard GJ, White RG. Tuberculosis prevention in South Africa. PLoS ONE. (2015) 10:e0122514. doi: 10.1371/journal.pone. 0122514

53. Alene KA, Nega A, Taye BW. Incidence and predictors of tuberculosis among adult people living with human immunodeficiency virus at the University of Gondar Referral Hospital, Northwest Ethiopia. BMJ Open. (2013) 13:292. doi: 10.1186/1471-2334-13-292

Conflict of Interest: The authors declare that the research was conducted in the absence of any commercial or financial relationships that could be construed as a potential conflict of interest.

Copyright $\odot 2019$ Mollel, Maokola, Todd, Msuya and Mahande. This is an openaccess article distributed under the terms of the Creative Commons Attribution License (CC BY). The use, distribution or reproduction in other forums is permitted, provided the original author(s) and the copyright owner(s) are credited and that the original publication in this journal is cited, in accordance with accepted academic practice. No use, distribution or reproduction is permitted which does not comply with these terms. 